\title{
Researches On the Representative Works and Performance Practices of
}

\section{Contemporary Jingdezhen Ceramic Painting}

\author{
WANG Fangli \\ Institute of Jingdezhen \\ Jingdezhen,Jiangxi,333000 China
}

\author{
Wu Junfang \\ Institute of Jingdezhen \\ Jingdezhen,Jiangxi,333000 China
}

\begin{abstract}
This article consists of the following parts: First, introduces the development of Jingdezhen ceramic painting in detail.Second, analyzes the performance practices of contemporary Jingdezhen ceramic painting from three aspects, such as the performance practices of the artists in Jingdezhen institutes.Finally, appreciates several representative works of contemporary Jingdezhen ceramic painting. In this article, the research on representative works and performance practices of contemporary Jingdezhen ceramic painting has a certain significance and guiding value.
\end{abstract}

Keywords- Ceramic Painting, Representative Works, Performance Practices

\section{THE DEVELOPMENT OF JINGDEZHEN CERAMIC PAINTING}

Diversity of contemporary Jingdezhen ceramic painting reflects the new artistic pursuits and aesthetic trends, which makes significant progress in the excavation of traditional ceramic craft and art spirit. Undoubtedly, it opens up a new situation of China's prosperity and development of ceramic art. In order to reflect ceramic painting artists'artistic ideas and highlight the personality development of ceramic painting, these artists often use clever idea and unique form to fully tap the potential beauty of ceramic materials. There are also many potters continue to explore the relationship between sculpture and graphic painting. In order to enrich the imagination of contemporary Jingdezhen ceramic painting and expand the development of ceramic painting, these artists like to use figurative, realism, symbolism, emotion, performance, installations, pop and other forms to conduct ceramic painting.

Unlike any previous era of the development of ceramic painting, the use of the new kiln and firing increasingly sophisticated methods provide more likely to promote the diversity of contemporary Jingdezhen ceramic painting performance practices.

Of course, ceramic painting works also have the differences in the level: mature and immature, elegant and vulgar. Due to the complexity and diversity of contemporary Jingdezhen ceramic painting, it is difficult to make a clear definition of contemporary ceramics painting for us according to genre and style.
Currently, according to the trend of Jingdezhen Ceramic painting, traditional ceramic painting is still dominant in the market, the reason is multifaceted. From the perspective of a ceramic painter, who can perfectly combine ceramics with painting is probably the excellent local potter. These potters from generation to generation, through their efforts and experience, they naturally mastered the pottery technique. However, although foreign artists' drawing skill is good, they are not able to master ceramics quickly. In addition, the price of local ceramic works is relatively high, because people sought local ceramic artists. However, people are not optimistic about foreign artists and their works.

\section{ANALYSIS OF PERFORMANCE PRACTICES OF CONTEMPORARY JINGDEZHEN CERAMIC PAINTING}

\section{A. Analysis of performance practices of the artists in Jingdezhen institutes}

The ceramic painting artists in Jingdezhen institutes fully draw on traditional performance forms of Chinese painting, while they change the traditional techniques and traditional styles. For example, the ceramic painting artists like to combine monotone color underglaze blue with overglaze to form a comprehensive decoration, which can make blue and white decoration become more colorful. However, the traditional techniques generally do not allow such behavior. In short, new ceramic painting techniques enrich the expression of the screen,enhance the color effects of the screen and improve the expressive of the work. Contemporary representative works in Jingdezhen institutes generally have elegant classical temperament, which reflects Chinese traditional aesthetic sense and constitutes unique aesthetic characteristics of Jingdezhen ceramic art. Ceramic painting artists in Jingdezhen institutes seek a new breakthrough in the traditional ceramics, and the contents of the painting are traditional themes in general. In short, they prefer to innovate in the traditional basis.

\section{B. Analysis of Jingdezhen folk ceramic painting artists' performance practices}

Jingdezhen folk ceramic painting artists have distinctive inheritance marks on the forms and methods of ceramic painting, such as character clothing color, because they are 
mostly the mentoring relationship or a parent-child relationship. The works of contemporary folk ceramic painting artists imply cultural essence of folk ceramic, and these ceramic paintings express the timeless beauty of the Oriental ceramic painting style. Jingdezhen folk ceramic painting artists pay great attention to the mentoring relationship, they are adhering to creative ideas of the previous generation from the subject and technique.

\section{Analysis of ceramic painting artists' performance practices of Jingdezhen art schools}

The manifestations of contemporary ceramic painting artists in Jingdezhen art schools are diverse. In order to reflect the new artistic pursuits and aesthetic trends, these ceramic artists like to create ceramic paintings with full modern consciousness, and their ceramic paintings have distinct personalities and unique forms of expression.Conducting ceramic painting, these ceramic artists emphasize to promote performance practices which combine modeling language with ceramic painting. In order to achieve the way of thinking and artistic forms of harmony and unity, ceramic painting artists do their best to explore and play the essence of creation during the traditional ceramic painting.

Glaze color is an important manifestation of ceramic painting, usually including the new color, ink color, the ancient color, pastels and so on. There are many varieties of glaze color, the color will not change great before and after the decorating. Overglaze presents a strong oriental flavor and Chinese national colors, fine glaze color is very popular. Glaze color not only can express beautiful wonderland ,but also can show the magnificent natural scenery.

High temperature color glaze ceramic painting is a new kind of painting language expression, and it refers to directly use the high-temperature color glaze on the green to paint, and fires at temperatures above 1300 degrees. High temperature color glaze is unique, ceramic painting shows the unique artistic charm by high temperature kiln.

Artists in Jingdezhen art institutions have received formal art education, they respect the laws of artistic creation, they also have good basic skills of painting, aesthetic skills and pay attention to personal artistic expression.Some artists in art schools use the concept of Chinese paintings to express the author's artistic concept, which fully reflects contemporary artists in the art institute to explore Jingdezhen Ceramic Painting new methods.

\section{THE APPRECIATION OF THE REPRESENTATIVE WORKS OF CONTEMPORARY JINGDEZHEN CERAMIC PAINTING}

\section{A. The appreciation of the representative works of the artists in Jingdezhen institutes}

Mr. Wang Xiliang is the author of the following painting, this work pay attention to the conception and focuses on decorative, the composition of this work is rather clever and natural, in order to pursue the artistic effect of still waters run deep. Simplicity is the most significant style in the works of Mr. Wang Xiliang, elegant charm describes Mr. Wang
Xiliang peaceful feelings. Vigorous pine, elegant figure, and even elegant gathers of characters, this painting shows a charm.

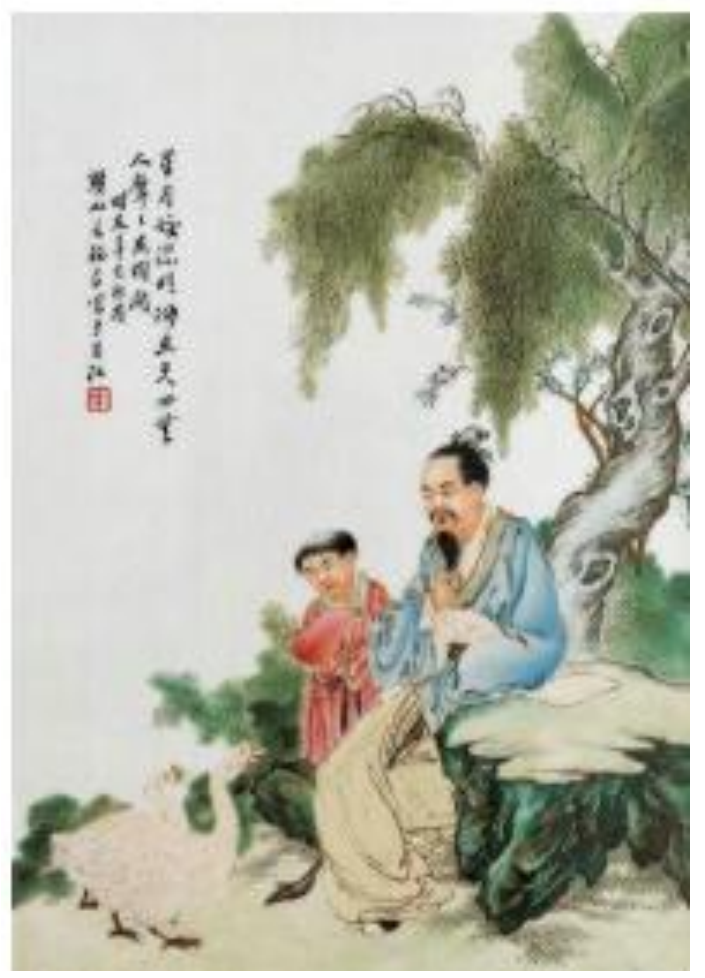

Mr. Zhang Songmao is the author of the following painting, this work recounts a very famous story in Chinese history, this work tells the story about Liu Bei went to the cottage three times and please Zhu Geliang. This work uses pastel to describe snow, as if we can see the vast expanse of mountains and plains. From this painting, we can see that nature is the most significant style in the works of Mr. Zhang Songmao.

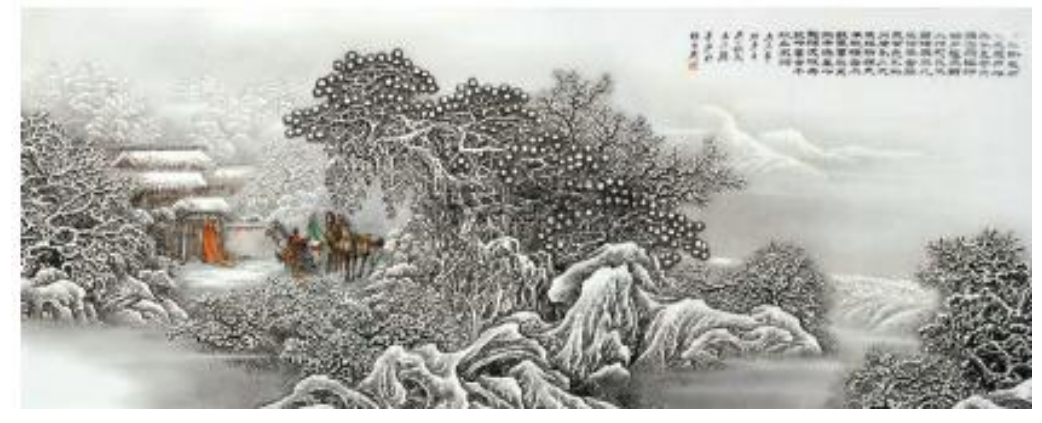

\section{B. The appreciation of Jingdezhen folk ceramic painting artists' representative works}

$\mathrm{Mr}$. $\mathrm{Lu} \mathrm{Ru}$ is the author of the following painting, the inspiration of this work is plum bamboo, the author added many elements of Chinese painting. The composition of the painting is very elegant, this work also express the author peaceful feelings. The author pays attention to the tricks of the screen structure, the screen structure is very coordinated. 


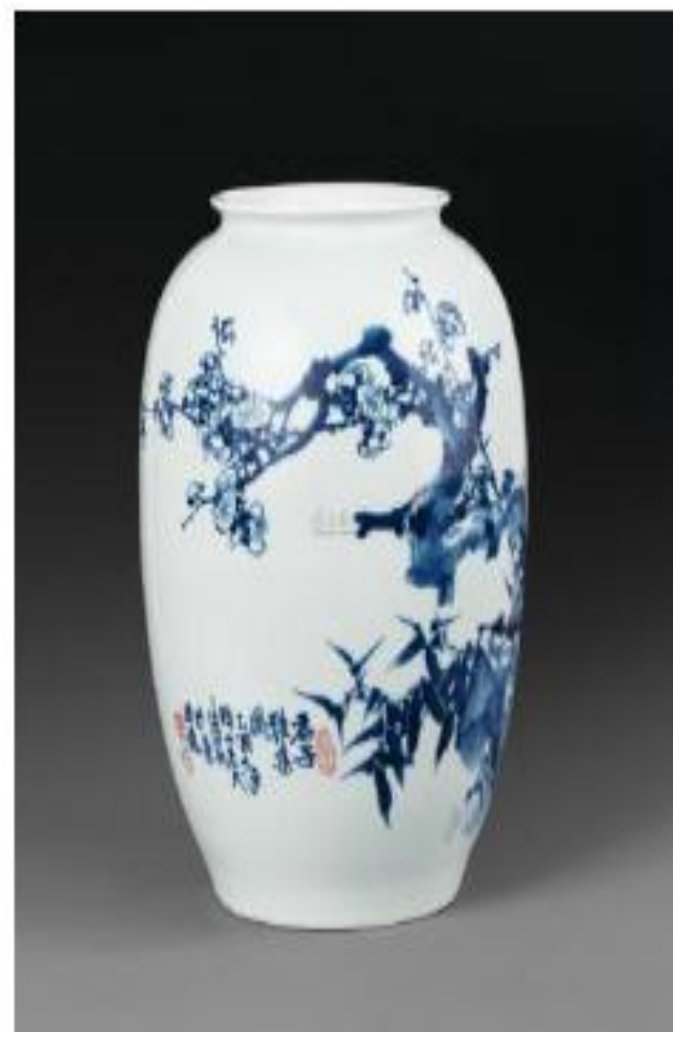

\section{The appreciation of ceramic painting}

artists'representative works of Jingdezhen art schools

Mr. Qin Xilin is the author of the following painting, this work uses Jingdezhen traditional blue underglaze red to carry out the performance. This painting not only has a strong modern aesthetic

sense, but also has the rhythm beauty of Chinese calligraphy. Screen gives a light pleasure to people, this painting also has a strong flavor of the times and the Oriental aesthetic characteristics.

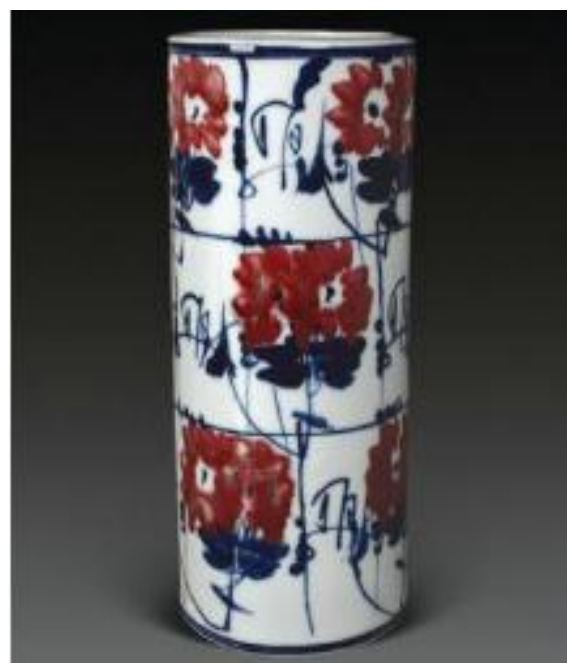

Mr. Zhong Liansheng is the author of the following painting, The painting depicts seven different attitude monkeys, these monkeys distributes patchwork in the picture to form a clever semicircle. Screen is very interesting and delicate, and also mixes in some elements of the Western watercolor. This painting shows us a dream-like mood, this mood has become one of his great artistic characteristics.

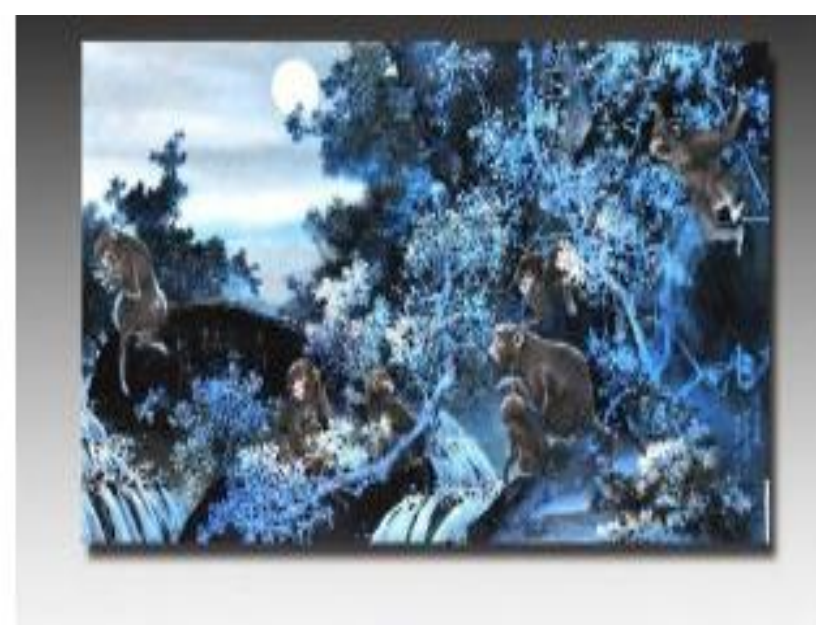

\section{CONCLUSION}

In fact, the division of ceramic painting artists in Jingdezhen art institutes, folk ceramic painting artists,ceramic painting artists in Jingdezhen art colleges is not absolute. These ceramic painting artists are mutually learn from each other, they influence each other in an interactive way. The performance practices of contemporary Jingdezhen ceramic painting break the traditional ceramic single state, these artistic expressions more combined with people's aesthetic. These artists continue to promote the innovation of ceramic painting, and also promote the diversity of contemporary Jingdezhen ceramic painting.

\section{INTRODUCTION OF AUTHORS}

WANG Fang-Li, female, Leping, Jiangxi Province, born in December 1977, master, fine arts (art and design)

\section{REFERENCES}

[1] GAN Zhi Yuan. Ceramic painting and ceramics inquiry [D]. Jingdezhen Ceramic Institute, 2013.

[2] ZHANG Chao. Effects of high temperature glaze Jingdezhen Ceramic painting contemporary artistic beauty of [D]. Jingdezhen Ceramic Institute, 2013.

[3] YAN Chun Feng. Contemporary Jingdezhen Ceramic Painting Status Dynasty [D]. Jingdezhen Ceramic Institute, 2013.

[4] MA En Jie. Contemporary ceramics painting diversity of manifestations of [D]. Jingdezhen Ceramic Institute, 2013.

[5] JIANG Na. Contemporary art painting pastels Jingdezhen sexual performance language study [D]. Jingdezhen Ceramic Institute, 2012. 